\title{
A FENOMENOLOGIA DO DIREITO E O PENSAMENTO DE ADOLPH REINACH'
}

\author{
Vivianne Geraldes Ferreira \\ Graduada pela Faculdade de Direito da \\ Universidade de São Paulo
}

\begin{abstract}
Resumo:
O presente trabalho apresenta o estudo do Direito, a partir da teoria de Adolph Reinach, sob uma perspectiva fenomenológica, buscando demonstrar a existência de conceitos jurídicos apriorísticos. Segundo A. Reinach, da mesma forma que são os números independentes da ciência matemática, e de toda $\mathrm{e}$ qualquer compreensão humana, existem conceitos juridicos essencialmente independentes de todo e qualquer Direito Positivo, existentes a priori e intelectualmente evidentes, como por exemplo, a promessa enquanto fonte de pretensões e obrigações. Estes conceitos jurídicos puros são descobertos pelo Direito Positivo, e não por ele criados.
\end{abstract}

\begin{abstract}
:
This work presents the study of Law, based on the doctrine of Adolph Reinach, under a phenomenological perspective, intending to prove the existence of a priori legal concepts. According to A. Reinach, as well as numbers are independent of any and all mathematical theory, and also of any human comprehension, there are legal concepts essentially independent of any and all Positive Law, existing a priori and intellectually evident, as, for example, promise as source of rights and obligations. These juridical concepts are discovered by Positive Law, and not created by it.
\end{abstract}

Unitermos: Direito apriorístico; fenomenologia; Adolph Reinach.

\section{A proposta de A. Reinach.}

A busca pela definição do que é o Direito é, também, a busca por alguma estrutura. É inerente ao homem, mergulhado no caos de sua própria existência, a busca por certeza ${ }^{2}$ O objetivo de A. Reinach foi pensar fenomenologicamente sobre o Direito, buscando por sua estrutura, ou seja, pelo seu ser puro, independente de qualquer conceito jurídico positivo, ou mesmo jusnatural.

1. O presente artigo foi claborado a partir de pesquisa realizada durante bolsa de iniciaçào científica, concedida pela Fundação de Amparo à Pesquisa do Estado de São Paulo - FAPESP (2001/2002). A autora foi orientada pelo Professor Doutor Ari Marcelo Solon, professor associado do Departamento de Filosofia c Tcoria Geral do Dircito da Faculdade de Direito da Universidade de São Paulo.

2. FLUSSER, Villem, Lingua e realidade, São Paulo, Herder, 1963. 
A. Reinach ${ }^{3}$ (1883-1917) foi aluno de E. Husserl, tendo sido profundamente influenciado pelas idéias da Escola Fenomenológica. E. Husserl deve, inclusive, conforme agradecimento presente no prólogo de suas Investigações Lógicas, a reedição deste trabalho ao incentivo e colaboração de A. Reinach. Quando da fundação do Jahrbuch für Philosophie und phänomenologie Forschung, E. Husserl convidou A. Reinach para ser um dos redatores - onde foi inicialmente publicada a obra por nós estudada. No início da Primeira Guerra Mundial, lecionava A. Reinach filosofia na Universidade de Göttingen, tendo morrido no ano de 1917 no campo de batalha, após ter se convertido no front à religião protestante.

Zur Phänomenologie des Rechts: die apriorischen Grundlagen des burgerlichen Rechts ${ }^{4}$ sua obra mais extensa e valiosa, foi publicada no Jahrbuch für Philosophie und phänomenologie Forschung do ano de 1913 (pp. 685/847). É um convite àqueles que desejam pensar fenomenologicamente sobre o Direito. Para A. Reinach, a fenomenologia é o método de filosofar exigido pela problemática filosófica, e também pela Filosofia do Direito, perdida em meio a teorias gerais de Direito Positivo.

Todo e qualquer Direito Positivo é fruto dos conceitos morais e econômicos de sua época, sendo seu conteúdo necessariamente dado pelo tempo. Não é possível a existência de qualquer Direito Positivo que se encontre à margem da História, constituído por leis que existam em $s i$, independentemente das influências do tempo, como ocorre com as leis matemáticas. Estas leis, assim como os números e as formas geométricas, existem independentemente de sua verificação empírica, independentemente até mesmo da compreensão humana.

Através do estudo de determinado ordenamento jurídico positivo é possivel elaborar conceitos e normas gerais que se aplicam apenas a esta ordem jurídica. Este tem sido em grande parte o papel da Ciência do Direito - elaborar teorias gerais do Direito Positivo.

Ao propor estudar o Direito com claridade e evidência intelectual, A. Reinach coloca-se contra o positivismo desmedido e, utilizando-se da nova filosofia desenvolvida por E. Husserl, busca pelas leis e conceitos jurídicos existentes a priori.

Para a fenomenologia do Direito ${ }^{5}$ os conceitos jurídicos não são criados

3. As informaçõcs disponivcis sobrc A. Reinach sào quasc tào cscassas quanto sua obra. As considerações sobre a vida destc filósofo foram obtidas no prólogo de J. M. A. M. Taladriz à cdição espanhola de Los fundamentos aprioristicos del derecho civil.

4. Em nossa pesquisa foi utilizada a tradução cspanhola de Josć Luis Álvarez (REINACH, Adolph, Los fundamentos aprioristicos del derecho civil, Barcelona, Bosch, 1934).

5. O objctivo de A. Reinach foi aplicar a fenomenologia ao Dircito, alcançando a essência de scus conccitos c formaçõcs. Desta forma, scria cntão cstudada a ciência pura do Dircito. Interessante ressaltar que também foi cste, de certa forma, o objetivo de H. Kelsen: o desenvolvimento de uma ciência pura do dircito, destituida de qualquer elemento que nào scja juridico, "purificada de toda a ideologia politica e de todos os elementos de ciência natural, uma teoria juridica consciente de sua especificidade porque consciente da legalidade especifica do seu objeto." (KELSEN, Hans, Teoria Pura do Direito, São Paulo, Martins Fontes, 1998, p. XI). No entanto, H. Kelsen desenvolveu uma tcoria pura do Dircito Positivo, livre de qualquer relação com a metafisica. 
pelo direito positivo, mas sim encontrados por ele. Há conceitos jurídicos que possuem um ser próprio, assim como os números, independentemente do Direito Positivo. A estrutura ôntica do Direito não pode ser obtida através da percepção, mas sim da intuição; o que intuímos vale estrita e legalmente para ela. O ser assim baseia-se na essência do que é assim.

A essência do Direito não apresenta as particularidades dos conceitos jurídicos existentes no Direito Positivo, mas sim o que vale universal e necessariamente, sendo que as variações de um mesmo conceito jurídico essencial serão regidas tanto pela essência deste mesmo conceito jurídico quanto pelas leis aprioristicas e conexões de essência a ele relacionadas. Portanto, para as formações jurídicas valem proposições aprioristicas.

O Direito apriorístico, como ciência de essências, é formado por objetos diferentes daqueles normalmente encontrados na natureza: não são objetos físicos nem psíquicos. Ao contrário: são objetos de um novo tipo, que possuem a particular característica de existirem por determinado período de tempo, sendo que para estes objetos valem leis apriorísticas. As leis apriorísticas - de essência - são eternas, mas os conceitos em si, verificados no mundo empírico, são temporais.

A um proprietário não é necessário explicar o que significa propriedade. Sua relação com a coisa que lhe pertence é imediatamente clara e evidente. A propriedade é, enquanto poder jurídico relacionado com a coisa, portanto, conceito jurídico puro, cuja existência é assegurada por leis e conexões essenciais - e não pelo Direito Positivo.

\section{A fenomenologia.}

A fenomenologia é fruto da necessidade de constituição de uma nova filosofia, "... a philosophy that - in contrast to the secondary productivity of renaissance philosophies - seeks by radically clarifying the sense and the motifs of philosophical problems to penetrate to that primal ground on whose basis those problems must find whatever solution is genuinely scientific." $\mathrm{A}$ fenomenologia busca, portanto, ir além do mundo natural: busca pela essência das coisas, pelas coisas como elas são.

O problema inicial da fenomenologia é o próprio problema do conhecimento. "Como pode o conhecimento estar certo da sua consonância com as coisas que existem em si, de as atingir?"

Ao falar em fenômenos puros, E. Husserl não pretende expressar essências que permanecem encerradas dentro de vivências, ou mesmo da razão, esperando para serem reveladas. Ao contrário, as essências se constituem, são exibidas através das vivências. As essências não se encontram encerradas dentro da razão, enviando sinais para a consciência. Não importa para a fenomenologia o fenômeno singular, mas o que nele se constitui. "A fenomenologia é ciência dos fenômenos cognoscitivos como

6. HUSSERL, Edmund, Pure phenomenology, its method and its fields of investigation, Notre Dame, University of Notre Dame, 1981, p. 1. 
fenômenos (Erscheinungen), manifestações, atos da consciência em que se exibem, se tornam conscientes, passiva ou ativamente, estas e aquelas objetalidades; $e$, por outro lado, ciência destas objetalidades enquanto a si mesmas se exibem deste modo. "7

A fenomenologia é, em primeiro lugar, o método próprio da teoria do conhecimento enquanto pensamento propriamente filosófico, e se dá pela busca da essência das coisas. Em razão da busca da fenomenologia pelo ente em sentido absoluto, existe o método fenomenológico enquanto atitude intelectual especificamente filosófica.

Os fenômenos são vivências interiores - dadas imediatamente à consciência através da intuição - de objetos exteriores. Estes últimos não interessam à fenomenologia, tampouco ao mundo natural, percepção, ciências empíricas etc. O objetivo da fenomenologia é alcançar a essência do fenômeno, ou seja, sua estrutura de significação.

O conhecimento natural implica a chamada "atitude teórica natural": começa e permanece encerrado na experiência. $O$ modo através do qual se dão seus objetos de investigação é a percepção, e seu campo de investigação é o mundo.

As ciências empiricas são, pois, ciências de fatos, ou seja, constatações empiricas - individuais - do mundo. Isto implica necessariamente a incerteza, já que os fatos são por natureza mutáveis e incertos: "... a universalidade empirica nada mais é do que uma extensão arbitrária de validade, pois se passa de uma validade que corresponde à maior parte dos casos, ao que corresponde a todos eles..." "8

A esta incerteza contrapõe-se a necessidade de existência de algo certo, puro, que lhe seja inerente: sua essência - eidos - que é sujeita a verdades essenciais com diferentes graus de universalidade. ${ }^{9}$ Toda coisa material tem sua própria forma essencial.

Esta essência pura é captada através da intuição essencial, em oposição à percepção em relação às ciências empíricas, e constitui um novo tipo de objeto, que se dá na intuição enquanto ele mesmo ${ }^{10}$

A relação existente entre determinando objeto individual, captado através da percepção, e a essência correspondente - sua essência - é o fundamento da relação existente entre ciências de fatos (empíricas) e as ciências de essências. "Hay ciencias de esencias puras... Estas ciencias son puras de todo poner hechos en todos sus pasos mentales; o, lo que es equivalente, en ellas no puede tomar la función de fundamentación la experiencia, esto es, en cuanto forma de conciencia que aprehende o pone la realidad o la experiencia." "Is ciências puras põem de lado toda a experiência como origem

7. HUSSERL, Edmund, A ideia da fenomenologia, Lisboa, 70, 2000, p. 34.

8. KANT, Immanucl, Crítica da razão pura, Rio de Janciro, Ediouro, p. 23.

9. HUSSERL, Edmund, Lleas relativás a una fenomenologia pura y una filosofia fenomenologica, Cidade do México, Fondo de Cultura Económiza, 1997, p. 19.

10. Da mesma forma, A. Reinach afirma que os conceitos juridicos puros configuram objetos temporais de uma nova espécic. Por csta razão, a fenomenologia ć uma ciência nova, que sc propõe a investigar o próprio conhecimento $\mathrm{c} o$ que se csconde atrás delc.

11. HUSSERL, Edmund, Ldeas relativas a una fenomenologia pura y una filosofia fenomenologica, Cidade do México, Fondo de Cultura Económiza, 1997, pp. 27/28. 
ou método de investigação. $O$ ato de fundamentação das ciências puras é a intuição essencial.

Disto resulta que toda ciência pura é absolutamente independente de toda e qualquer ciência de fatos. A partir de fatos têm-se somente fatos, e não essências. O mesmo, no entanto, não se passa com as ciências empíricas. ${ }^{12}$ "No hay ninguna que, plenamente desarollada como ciencia, pueda ser pura de conocimientos eidéticos $y$, por ende, pueda ser independiente de las ciencias eidéticas, ya formales, ya materiales. "13 Desta forma, ao se utilizar de fatos, as ciências empíricas inevitavelmente estarão lidando com essências. Ainda, quanto mais desenvolvida uma ciência empírica, mais intrinsecamente estará subordinada às ciências essenciais.

Desta investigação pelas coisas enquanto o que elas são, ou seja, de suas essências, E. Husserl conclui que são os fenomenologistas os verdadeiros positivistas. "Si positivismo quiere decir tanto como fundamentación, absolutamente exenta de prejuicios, de todas las ciencias en lo "positivo" en, pues, lo que se puede aprehender originariamente, entonces somos nosotros los verdaderos positivistas" 14

A essência de determinado objeto/fenômeno pode ser obtida através da intuição. A intuição para E. Husserl é a consciência de algo, livre e diretamente dirigida a ele. A intuição empírica ou individual é a percepção, que pode transformar-se em idéia, convertendo-se em intuição essencial. O que é intuído neste caso é a essência pura-eidos.

Para a fenomenologia, a intuição tem papel fundamental na apreensão do conhecimento. O homem transforma a vivência - cogitatio - intuitivamente em dado. A essência de certo objeto é intuitivamente obtida.

A fenomenologia busca pela claridade, pela compreensão da possibilidade deste apreender. O método fenomenológico, portanto, não pode ser o mesmo das ciências objetivas, pois o ver não pode demonstrar-se. Por esta razão, é necessário elevar-se intuitivamente além do conhecimento, alcançando essências universais.

É o princípio de todos os princípios que toda intuição imediata, na qual algo se dá originariamente, seja fundamento de conhecimento, devendo simplesmente ser tido como se dá. ${ }^{15}$

$\mathrm{Na}$ crítica do conhecimento através do método fenomenológico, num

12. Importante para a fenomenologia do Dircito observar que ciências puras são independentes de ciências empíricas, enquanto estas freqüentemente se desenvolvem conforme aquelas. Daqui resulta a independência do dircito aprioristico $\mathrm{cm}$ face do Dircito Positivo, cmbora cste freqüentemente encontrc os conccitos puros, e deles se utilize conforme as conveniências sociais, cconômicas, políticas c morais de sua ćpoca.

13. HUSSERL, Edmund, Ileas relativas a una fenomenologia pura y una filosofia fenomenologica, Cidade do México, Fondo de Cultura Económiza, 1997, p. 29.

14. HUSSERL, Edmund, Ideas relativas a una fenomenologia pura y una filosofia fenomenologica, Cidade do Mćxico, Fondo de Cultura Económiza, 1997, p. 52.

15. HUSSERL, Edmund, Ideas relativas a una fenomenologia pura y una filosofia fenomenologica, Cidade do Mćxico, Fondo de Cultura Económiza, 1997, p. 58. 
primeiro momento, todo conhecimento é colocado em questão. No entanto, por ter sido colocado em questão, não se pode dizer que ele não exista. Por esta razão é preciso partir de algum ponto indubitável.

Este ponto certo e indubitável, para E. Husserl, é a meditação cartesiana sobre a dúvida, ou cogitatio (vivência). A cogitatio é indubitável enquanto diretamente apreendida e experimentada: "o apreender e o ter intuitivos e direitos da cogitatio são já um conhecer"'16, e também pelo seu caráter de imanência - dada em si mesma.

A cogitatio é o fenômeno psicológico na percepção e objetivação psicológica, devendo também ser reduzido por não ser um dado absoluto, ou seja, por ser o próprio aparecer.

A "evidência da cogitatio" é o primeiro dado absoluto da teoria do conhecimento, que prescinde de elementos previamente dados. A cogitatio é o primeiro fenômeno cognoscitivo. Mas mesmo a vivência pode incluir dados transcendentes, como o "eu", por exemplo. Deve-se, então, proceder à redução fenomenológica. A busca da fenomenologia não é pelo fator psicológico, mas sim pelo que vale ainda que a realidade objetiva não exista.

O método de redução fenomenológica é a chave para a compreensão do que é a fenomenologia, sendo a grande inovação proposta por E. Husserl para fundação do que seria a verdadeira filosofia.

Num primeiro momento, o mundo é experimentado pelo homem em "atitude natural", através da apreensão da realidade assim como ela é dada, e em primeira pessoa. Porém, o mundo não se esgota no experimentado, e sim se estende no infinito, tanto temporal quanto espacial. Por esta razão o que é conhecido está permeado por um "horizonte oscuramente consciente de realidad indeterminada" 17

O mundo, embora permaneça o mesmo tal qual apresentado ao sujeito, tem seu conteúdo freqüientemente alterado, e não pode ser apreendido exatamente como ele é, visto ser contaminado pelos conceitos de espaço e tempo. Desta forma, o primeiro objeto de estudo fenomenológico deve ser uma forma fundamental de vida "atual": a cogito cartesiana. ${ }^{18} \mathrm{~A}$ atitude natural, por seus defeitos, não interessa à fenomenologia, que busca a claridade e certeza das "novas atitudes"

O instrumento metódico utilizado por E. Husserl para chegar ao fim da fenomenologia é a dúvida universal. É possível, com absoluta liberdade, duvidar de todas as coisas experimentadas. Esta dúvida perante algo efetivamente apreendido do mundo exterior acarreta necessariamente "cierta abolición de la tesis" ${ }^{19} \mathrm{O}$ que é

16. HUSSERL, Edmund, A ideia da fenomenologia, Lisboa, 70, 2000, p. 23.

17. HUSSERL, Edmund, Ideas relativas a una fenomenologia pura y una filosofia fenomenologica, Cidade do Mćxico, Fondo de Cultura Económiza, 1997, p. 65.

18. $\mathrm{Ncm}$ toda cogitatio referc-sc a objetos exteriores, embora constantemente o faça. Por csta razào, E. Husserl afirma ser possível a intuição de cssências através de representações ideais, fantasias.

19. HUSSERL, Edmund, Ideas relativas a una fenomenologia pura y una filosofia fenomenologica, Cidade do Mćxico, Fondo de Cultura Económiza, 1997, p. 71. 
separado da vivência continua existindo, porém passa a não ser mais considerado. Destaca-se do ser, através da dúvida, o não-ser.

A redução é o próprio ato de colocar entre parênteses tudo que é transcendente ao fenômeno, e este é o método próprio da fenomenologia proposto por E. Husserl. Através deste método, busca-se a certeza (essência) através dos fenômenos.

Mas o que deve ser colocado entre parênteses? Certo que não é tudo o que existe, ou-não restaria campo algum de estudo para a fenomenologia. "Ponemos fuera de juego la tesis general inherente a la esencia de la actitud natural. Colocamos entre paréntesis todas y cada una de las cosas abarcadas en sentido óntico por esa tesis, asi, pues, este mundo natural entero, que está constantemente "para nosotros ahi adelante", y que seguirá estándolo permanentemente, como realidad de que tenemos conciencia, aunque nos dé por colocarlo entre paréntesis" 20

A redução fenomenológica não coloca em questão a existência do mundo natural, mas sim retira das vivências internas todo juízo sobre existências temporais e espaciais. Nenhum uso, portanto, será feito das ciências naturais ou de suas leis. $\mathrm{O}$ que restaria, então, após a redução fenomenológica? O que não resiste à redução é o mundo como fato, e subsiste o mundo como eidos. A expressão consciência compreende a todas as vivências. Dentro da consciência devemos nos ater ao que existe essencialmente. " $L a$ conciencia tiene de suyo un ser propio, que, en lo que tiene de absolutamente propio, no resulta afectado por la desconexión fenomenologica.". ${ }^{21}$ Este ser é o resíduo fenomenológico, que espelha a região do ser. A redução é, portanto, o acesso à consciência pura.

3. Conceito jurídico puro: a promessa como fonte de pretensões e obrigações.

Segundo A. Reinach, a promessa não seria simplesmente a exteriorização da vontade. Seria, sim, uma essência pura, que cria um vínculo entre dois (ou mais) indivíduos, possui determinada duração e lhe é imanente que tenha determinado fim, seja através de seu cumprimento, renúncia ou revogação.

Primeiramente, são "produtos" da promessa duas formações jurídicas distintas: pretensão e obrigação. O que seriam, então, estas formações? Não se pode afirmar que nada são, pois nada não pode ter conseqüências no mundo externo, muito menos no mundo jurídico. Também não são objetos físicos, encontrados empiricamente no mundo ratural, nem ao menos vivências (objetos psíquicos). Não são, ainda, objetos ideais, que segundo sua própria essência são externos. Pretensão e obrigação são, portanto, objetos temporais de espécie singular. Para estas formações valem leis essenciais, imediatamente inteligíveis, como, por exemplo, a lei de que a pretensão se extinga através de seu cumprimento. Esta lei não é captada através da experiência, mas provém, sim, da essência da pretensão como tal, sendo válida geral e necessariamente.

20. HUSSERL, Edmund, Ideas relativas a una fenomenologia pura y una filosofia fenomenologica, Cidade do Mćxico, Fondo de Cultura Económiza, 1997, p. 73.

21. HUSSERL, Edmund, Ideas relativas a una fenomenologia pura y una filosofia fenomenologica, Cidadc do Mćxico, Fondo de Cultura Económiza, 1997, p. 76. 
É ainda proposição sintética, pois o predicado (extinção por cumprimento) não está contido no sujeito (pretensão).

É imanente à essência tanto da pretensão quanto da obrigação a presença de um portador - sujeito da pretensão ou obrigação - e de um conteúdo - conduta do portador. O conteúdo pode, segundo as leis de essência, ser uma conduta atual ou futura do portador. Ainda, o destinatário da obrigação não deve necessariamente ser o destinatário do conteúdo da obrigação.

Utilizando-se apenas da intuição, A. Reinach conclui que é lei geral, inteligível em si mesma, que pretensões e obrigações relativas devam ter um fundamento. Desta forma, sempre que esse mesmo acontecimento (fundamento) ocorrer, nascerá necessariamente uma nova pretensão ou obrigação. Existe, portanto, uma relação causal entre acontecimento/fundamento e a pretensão ou obrigação. ${ }^{22}$ No entanto, esta relação causal é diferente da relação causal que existe na natureza. A relação causal $a$ priori é conexão de essência, imediatamente inteligível e necessária, pois a experiência não participa de sua construção. "Un 'fundamento que puede producir pretensión y obligación es la promesa. De ella proceden - como mostraremos aún más de cercapretensión y obligación; podemos llegar a inteligirlo, presentándonos con toda claridad lo que es una promesa, e intuyendo que se basa en la esencia de tal acto producir pretensión y obligación bajo determinadas circunstancias. Asi, pues, de ningún modo es la experiencia la que nos enseña el entroncamiento existencial de estas formaciones, ni tampoco juega sólo un papel de cooperación; más bien, se trata de una conexión de esencia inmediatamente inteligible y necesaria" ${ }^{23}$

Existem, no mundo, esferas infinitas de vivências. Para o nosso estudo, segundo A. Reinach, interessam aquelas vivências que não só pertencem ao "eu", mas nas quais, também, o "eu" se mostre ativo. Estas vivências serão designadas como atos espontâneos. A algumas vivências, por outro lado, é essencial a existência de um outro sujeito para referência: são as vivências alheio-pessoais. Há atos, ainda, que além de se referirem a outro sujeito, são também dirigidos a este mesmo sujeito, devendo por este serem percebidas. Os atos espontâneos que, segundo sua essência, devem ser percebidos pelo outro sujeito são por A. Reinach chamados de atos sociais. ${ }^{24}$ Os atos sociais são vivências de uma espécie própria: não são apenas ação externa, vivência interna ou mera manifestação de uma vivência interna. São, sim, um fazer do sujeito espontâneo, intencional, que devem ser percebidos pelo outro sujeito.

A promessa é um ato alheio-pessoal, pois exige sujeito contrário - ao

22. Scgundo H. Kelsen, nào se pode afirmar que exista relaçào de causalidade no universo jurídico, c sim relação de imputação. Apesar de ambos os conccitos screm análogos, a relação de causalidade implica cm que se A ć, B ć. A rclação de imputação, própria do Dircito, diz que se A ć, B deve ser, ainda que necessariamente não seja (KELSEN, Hans, Teoria Pura do Direito, Sảo Paulo, Martins Fontes, 1996, pp. 100/102).

23. REINACH, Adolph, Los fundamentos aprioristicos del derecho civil, Barcelona, Bosch, 1934, p. 42.

24. Aos atos sociais ć fundamental a idéia de que devam ser percebidos, não sendo necessariamente atos alheio-pessoais. 
qual se promete - e pressupõe a existência de determinada vivência interna, que é a intenção (vontade de prometer). Não é, porém, a simples declaração de vontade, ${ }^{25}$ que constitui comunicação. É, sim, um ato espontâneo que produz efeitos ao penetrar no mundo exterior, independente da vontade, embora esta esteja em sua base. Para distinguir a promessa da simples declaração de vontade, é importante verificar o contexto lingüístico utilizado. A promessa deverá apresentar todas as características essenciais acima apresentadas.

A promessa é fonte de pretensões e obrigações. Não é suficiente à promessa, no entanto, que aquele ao qual ela se dirija a ouça, sem compreendê-la. É lei de essência que este segundo sujeito compreenda e tome conhecimento daquele ato como promessa. Por outro lado, não é necessária a aceitação, ou sua exteriorização, para que dela nasçam pretensões e obrigações. A relação criada por uma promessa é uma relação obrigatória.

Toda promessa tende à sua extinção, ou seja, à realização de seu conteúdo. Esta tendência ao cumprimento é transcendente à promessa, não sendo predicado seu. Baseia-se a priori na essência da pretensão, e não na promessa, enquanto tal.

A obrigação também pode ser anulada, o que, porém, não pertence à sua essência. A priori, a promessa não pode ser revogada. Ela existe e deve ser cumprida. O sujeito capaz de discutir sua validade e revogá-la é o portador da pretensão destinatário da promessa. A revogação, em si, é ineficaz. Apenas com a renúncia nasce um poder eficaz sobre a relação social, e este poder é um poder jurídico. Assim, sob certas hipóteses, pode ser possível a revogação de uma promessa através de um poder jurídico. No entanto, somente o portador da pretensão pode conceder tal poder ao portador da obrigação.

Estas são as características essenciais da promessa: (i) pretensão e (ii) obrigação. São elas regidas por leis certas e invariáveis, apesar do que dispõe o direito positivo vigente.

O propósito de A. Reinach não foi formular uma teoria da promessa, e sim evidenciar que a promessa, enquanto tal, cria pretensões e obrigações. A promessa é um ser dado, e explicá-la, além de todas as linhas fundamentais expostas, tem o mesmo sentido de explicar que 1 X $1=1$.

As conexões apriorísticas possuem uma dignidade que lhes é própria, apesar de serem fragilmente - através da intuição - dadas. De forma alguma dependem elas do Direito Positivo, ou da compreensão - e até mesmo existência - do próprio homem. ${ }^{26}$

25. É geralmente accita pela doutrina a idéia de que a promessa scja uma declaração de vontade. No entanto, ć intercssante notar que tambćm C. M. S. Percira atribui como requisito do vínculo obrigacional ser a promessa dirigida a algućm, alćm de ser fonte de dircitos c obrigações (PEREIRA, Caio Mário da Silva, Instituições de Direito Civil, vol. III, 3a edição, Rio de Janciro, Forense, 1998, pp. 349/350).

26. Para H. Kelsen, falar sobre uma obrigação, dando-lhe o nome de dever jurídico, ć falar na verdade sobre uma norma juridica que age sobre determinada conduta. O conceito de dever juridico teria como objeto ligar às obrigaçõcs criadas por normas juridicas certo caráter moral absoluto (KELSEN, Hans, Teoria pura do direito, São Paulo, Martins Fontes, 1996, pp. 128/133). 


\section{A fenomenologia do Direito e a dicotomia Direito Positivo e Direito Natural.}

"O Direito, como ciência sistemática, divide-se em Direito Natural que se funda em principios puramente a priori, e em Direito Positivo (regulamentar). que tem por principio a vontade do legislador... Há somente um único direito natura. ou inato", 27

Esta é a tradicional divisão a que se submete o Direito. De um lado, or melhor, acima, está o Direito Natural, imutável e, como reflexo da Justiça que é, superios ao Direito Positivo. De outro, o próprio Direito Positivo, representado pelas normas juridicas de determinado ordenamento.

É característica do Direito Natural sua aproximação com a Moral. Têm em comum as diversas correntes jusnaturalistas a defesa da existência princípios de conduta humana que são descobertos pela razão e devem ser observados pelo homem e, principalmente, pelo Direito Positivo, já que sua validade deriva desses princípios.

A. Reinach defende um novo estudo do fenômeno jurídico. Segundo ele, também o Direito possui conceitos que existem independentemente do Direito Positivo, assim como os números existem independentemente da ciência matemática. O Direito Positivo não cria conceitos jurídicos, e sim os encontra. Através do método fenomenológico, e principalmente da intuição, é possível chegar à essência das formações jurídicas e ao que vale estrita e essencialmente para elas. Os conceitos jurídicos a priori são, portanto, aqueles que, no sentido dado, são gerais e existem necessariamente.

Por outro lado, o Direito Natural - dada sua aproximação da Moral não sobrevive à redução fenomenológica: para colocar o ser entre parênteses e captat somente sua essência, deve-se dar valor zero também ao homem, que é o palco dos valores morais.

A. Reinach afirma ser provável que a também a doutrina do Direito apriorístico seja apontada como de natureza jusnaturalista. Não deve, no entanto, seı confundida a doutrina apriorística do Direito com as teorias de Direito Natural. "El derecho natural se há equivocado, ante todo, en dos puntos: en el tratamiento dei derecho positivo y em el proyecto de un derecho material y, no obstante, válido incondicional y generalmente" ${ }^{28}$ O Direito apriorístico é independente de todo e qualquer Direito: do vigente, do válido e do pensado como válido.

O Direito Natural é colocado por seus defensores como superior ac Direito Positivo vigente. Por esta razão, deveria ser utilizado para suprir as lacunas existentes e deixadas pelo Direito Positivo. Suas normas, ainda, deveriam ser suas normas aplicadas em detrimento das normas de Direito Positivo, caso existisse entre elas conflito. O mesmo, no entanto, não é válido para a doutrina apriorística do Direito.

27. KANT, Immanucl, Doutrina do Direito, São Paulo, Conc, 1993, p. 55.

28. REINACH, Adolph, Los fundamentos aprioristicos del derecho civil, Barcelona, Bosch, 1934, p 221. 
A pureza do Direito a priori consiste em ser ele totalmente independente do Direito Positivo, bem como de normas jusnaturais, sendo ainda indiferente à sociedade e seu tempo, valores, desejos e necessidades. São leis do ser, que podem até mesmo ser tidas pelo Direito Positivo como algo que não deve ser. O Direito puro vale em si e para si.

Em muitos campos da sociedade existe regulação por normas não-escritas de origem apriorística. No entanto, tal fato não autoriza, de forma alguma, recorrer-se indiscriminadamente ao Direito puro. Deve este ser guia do legislador, e não do juiz na análise do caso concreto.

Não deriva o Direito apriorístico da natureza das coisas - como seria o Direito Natural - pois suas legalidades são sustentadas por si mesmas e são indiferentes aos homens e à própria natureza, tais quais seus objetos, que não são físicos ou psíquicos por não pertencerem à natureza. Tal qual conceitos matemáticos, sua existência é indiferente ao conhecimento, a seu respeito, pelos homens. As leis aprioristicas valem não-somente para este mundo de homens, mas para qualquer mundo pensável.

Por outro lado, temos uma aparente contradição entre Direito Positivo e Direito apriorístico. A despeito de toda a evidência intelectual que cerca os conceitos essenciais expostos pelo autor, dentre os quais a promessa, sobre a qual nos detivemos neste trabalho, parece que todos eles, bem como legalidades e conexões essenciais, são contrariados pelo Direito Positivo. Como falar na validade absoluta do Direito $a$ priori, já que o Direito Positivo pode contrariá-lo? Existe, então, contradição entre as proposições do Direito apriorístico e as normas do Direito Positivo?

Certamente, somente podemos falar em contradição entre proposições de espécie determinada e idêntica de conteúdos contraditórios. Neste sentido, não existe contradição entre Direito apriorístico e Direito Positivo.

As proposições do Direito apriorístico são proposições de juizo, pois põem o ser como existente, sendo ainda a relação entre dois conceitos - sujeito e predicado. São as proposições de Direito Positivo também proposições de juizo? Geralmente é aceita a idéia de que as proposições de Direito Positivo são, sim, proposições de juízo hipotético. Porém, na verdade não são nem proposições de juízo, muito menos hipotéticos. Não temos em relação às proposições de Direito apriorístico a existência de um ser que se poderia julgar como verdadeiro ou falso, conforme existisse ou não o ser. As proposições de Direito Positivo são, na verdade, determinações, que não podem sofrer julgamento sobre serem verdadeiras ou falsas. $O$ motivo da confusão entre Direito apriorístico e Direito Positivo existe em razão de coisas diferentes serem expressas com as mesmas palavras. A doutrina afirma (julga), com base em determinações de Direito Positivo, e suas afirmações (juízos) podem ser verdadeiras ou falsas. Porém, as determinações do Direito Positivo podem, em si, ser vigentes ou não, justas ou injustas, mas não verdadeiras ou falsas. Desta forma, não existe contradição autêntica entre as leis de essência e o Direito Positivo, pois não são equivalentes, nem existem em si.

As determinações do Direito Positivo também não são ordens. Apesar de ordem e determinação serem atos sociais, por necessitarem de percepção para serem 
válidas, a determinação não é ato alheio-pessoal. Sua substância não exige uma circunstância pessoal, apesar de sua execução ser dirigida a pessoas. O conteúdo de ambos os atos também é diferente. A ordem sobre conduta é dirigida à pessoa que é ordenada. A determinação, por outro lado, não assume esta "direção" pessoal.

A ordem, ainda, pressupõe como vivência interna a vontade de que algo certo e determinado seja feito. A vontade que fundamenta a determinação tem caráter geral de que algo deva ser. A partir da determinação, no entanto, nasce uma ordem a uma pessoa determinada, ou seja, à pessoa que deva executar ${ }^{29}$ o quanto determinado.

A determinação, em si, não deve ser confundida com sua vivência, ato, proposição, conteúdo ou efeito de determinação. $O$ ato de determinação (A deve ser $B$ ) difere da proposição de determinação, que é a objetivação do ato de determinação. As proposições de determinação são encontradas, por exemplo, nos códigos, e configuram determinações do tipo "faça isto", não expressando nenhum juízo.

O conteúdo da determinação, por outro lado, pode expressar um juizo, ou seja, o dever-ser de certo estado de coisas, ou uma ordem dirigida a conduta das pessoas. Pode ser, sim, conteúdo de determinação uma conduta própria. ${ }^{30} \mathrm{Na}$ verdade, estas duas possibilidades essenciais de conteúdo das determinações expressam diferentes formas de desenvolvimento dos atos. Os juízos, por exemplo, são atos de adaptação. ${ }^{31}$ A essência refere-se a algo existente. Se este algo não existe, o julgador deverá fazer uma adaptação, ou seja, considerá-lo como existente, ou seja, que exista em si. Assim, em princípio é possível que a determinação tenha como conteúdo algo que não exista efetivamente, ou seja, que não possua essência correlata. A determinação é livre e tem caráter temporal, sendo relacionada somente ao ato do determinante. Por outro lado, se existe um dever, não há que se falar em adaptação, pois a determinação passará a reger dever já existente.

Pode-se falar, em relação às determinações, sobre eficácia. São eficazes os atos que por sua execução querem efetivar algo e eventualmente efetivem certa modificação no mundo exterior. Quem determina o faz em relação ao tempo - agora e a um determinado número de pessoas. Esta é a vigência das determinações.

Toda determinação, por sua natureza, tende a sua realização, ou seja, a realização do que põe como devendo-ser. Este dever-ser, para que possa tender à realização, não pode ser a priori necessário ou impossível. ${ }^{32}$ Só é conteúdo de

29. Sc A deve scr B, cntão farci B - csta ć a cxecuçào da determinação.

30. Por csta razão, o Estado se submetc a suas própriás leis.

31. Os atos de adaptação podem scr logicamente cxatos ou incxatos. Scrào cxatos se realmente cxisṭ o que põcm como cxistentc.

32. Evidente aqui a influência sobre A. Reinach de scu tempo. Também H. Kelscn afirma que o contcúdo de uma norma jurídica não pode ser necessário ou impossívcl, não atingindo a cficácia/vigência da norma a possibilidade de ser desrespeitada. "Uma norma que preceituasse um certo fato que de antemão se sabe que necessariamente se tem de verificar, sempre e em toda parte, por força de uma lei natural, seria tão absurda como uma norma que preceituasse um certo fato que de antemão se sabe que de forma alguma se poderá verificar, igualmente por força de uma lei natural" (KELSEN, Hans, Teoria Pura do Direito, 6a cd., Sào Paulo, Martins Fontes, 1998, p. 12). 
determinação o que possa ou não ser, ou seja, o que possa ou não ser cumprido, e deve ainda ser temporal, ter determinada duração. Se a determinação é eficaz, ela existe para seus receptores como devendo-ser. Este dever-ser se constitui no próprio ato de determinação e vale perante aqueles que o consideram eficaz. No ato de determinação incluem-se três tipos de dever, que não se confundem com deveres morais: "el deber ser existente en si que fundamenta las determinaciones que le ponen como algo a realizar; el deber ser que se constituye en el acto que vale para un determinado circulo de personas, que nace de todas las determinaciones eficaces, estén o no fundamentadas; $y$, en fin, el mero estar puesto como debiendo ser, que existe relativo a todas las determinaciones fundamentadas e infundamentadas, eficaces e ineficaces" 33

Assim, ao lado dos objetos de natureza física e psíquica, A. Reinach apontou a existência de objetos de um novo tipo, objetos temporais que nascem dos atos sociais. No entanto, a partir das determinações nasce uma realização necessária mas não totalmente obrigatória - do que deve-ser, o que não ocorre com tais objetos temporais. As determinações não são realmente capazes de criar automaticamente o dever-ser objetivo, ou seja, a conduta determinada. Mas, através delas mesmas nasce o que deve-ser, se executada a conduta. O exemplo dado por A. Reinach é o da determinação por um juiz acerca da transferência ou atribuição de certa propriedade a uma pessoa, e a determinação da atribuição do direito de receber pagamento a outra pessoa, ex-proprietária. A obrigação de pagamento não nasce imediatamente a partir dos atos sociais praticados por estas duas pessoas, mas sim da determinação em si do juiz. Não é necessário que se realize o pagamento para que se opere uma modificação no mundo exterior. A conduta determinada já é real no momento da determinação, e apenas por ela.

Quais seriam, então, os pressupostos de eficácia das determinações? O agente determinante deve ter o poder de criar determinações que vinculem pessoas, poder este que deve ter sido outorgado por estas mesmas pessoas. A determinação não cria um direito, mas torna eficaz certa pretensão preexistente: assim nasce uma segunda - e nova - pretensão de que a parte condicionada realize a primeira pretensão preexistente. "Vemos, y es lo esencial, que en todos estos casos la determinación no tiene fuerza directa creadora de derechos; sólo provoca una especialización de derechos y obligaciones que fluyen de otras fuentes" ${ }^{34}$ A submissão - ato social e alheio-pessoal - equivale a uma declaração, à pessoa que determina, do tipo "deve ser assim, conforme o determinado", ocorrendo a outorga do poder de produzir em si efeitos jurídicos.

As determinações não têm força suficiente para derrogar conexões apriorísticas. Pelo contrário, pressupõem sua validade. A função das determinações é criar formações juridicas que não existem a priori, ou tornar ineficazes formações 178.

33. REINACH, Adolph, Los fundamentos aprioristicos del derecho civil, Barcclona, Bosch, 1934, p.

34. REINACH, Adolph, Los fundamentos aprioristicos del derecho civil, Barcelona, Bosch, 1934, p. 180. 
jurídicas existentes em decorrência de conexões apriorísticas. Afinal, examinando $\mathrm{c}$ estado de coisas, o ser assim pode não coincidir necessariamente com o dever-ser, por motivos morais, econômicos, políticos etc. $O$ dever ser não é suficiente para afetar o Direito a priori em si e para si, devendo-se a ele somar outros fatores que fundamentam a exclusão de certa formação jurídica aprioristica. Estes fatores são a função da determinação.

Assim como as leis do ser, as proposições do dever-ser admitem fórmula geral. As pessoas podem, portanto, submeter-se, para regular relações jurídicas entre $\mathrm{si}$, a determinações gerais de outras pessoas. Estas determinações gerais diferem das determinações concretas, que criam ou destroem legalidades próprias do ser. "Supongamos primeramente que exista una conexión aprioristica, según la que sea imposible que ciertas formaciones juridicas nazcan de determinados actos sociales (una pertenencia, p. ej., de uma promesa). Entonces, naturalmente, la determinación no puede hacer que a pesar de todo llegue aquel nacimiento. Solo tenderá a que cuantas veces se ejecute un acto social de aquella espécie, deba nacer inmediatamente la formación juridica. Si tal determinación es eficaz, nace en realidad; pero nunca por la promesa, sino según la promesa y por determinación" 35 O mesmo não ocorre com conexão de necessidade. Se uma determinação impede a ocorrência de certa conexão essencial, determinando o nascimento de ato diverso daquele que a priori nasceria, não é esta determinação capaz de gerar tal ato, diferente da essência do vínculo em questão, mas sim age impedindo efetivamente a ocorrência da conexão entre eles. $O$ vigor da conexão de essência é retirado pela determinação, apesar desta pressupor sua existência.

Por outro lado, podemos distinguir dois tipos de conexão de essência: i. aquelas que valem em todas as circunstâncias; e ii. aquelas que valem desde que não exista certo estado de fato. Neste último caso, não significa que o ato não exista, mas sim que em algumas circunstâncias ele não é válido, ou melhor, não é vigente. Apenas em si e por si possuem vigência sem exceção. ${ }^{36}$

O ato e sua objetivação (proposição de determinação, tal qual uma norma jurídica presente em um código) compõem o que deverá ser. Para A. Reinach a fundamentação ou validade decorre do fato do dever ser corresponder ao dever ser em si (o que é). Sua eficácia ou vigência decorrem do conteúdo do dever, que encontrará sua objetividade junto ao grupo de pessoal ao qual se dirige.

Após todas as considerações acima apresentadas, é o momento de se rechaçar a "contradição" aparentemente existente entre a doutrina apriorística do Direito e o Direito Positivo, divergência esta existente em razão de diferenças entre as leis do 183.

35. REINACH, Adolph, Los fimclamentos aprioristicos del derecho civil, Barcclona, Bosch, 1934, p.

36. Esta ć uma das relaçõcs cxistentes cntre Dircito aprioristico c Dircito Positivo. Com cfeito, ́ facultado ao legislador - c não ao juiz - reconhecer ou não a validade de determinada concxão aprioristica. Sc não o fizcr, a concxão aprioristica não terá dcixado de cxistir, apcnas não tendo vigência cm face de tal detcrminação. 
ser e as determinações do dever-ser - o que impossibilitou o acesso às conexões jurídicas de essência.

Não podem ser tais divergências ou contradições argumentos contra o Direito apriorístico, visto que é justamente a existência de conexões de essência que tornam evidentes e possíveis tais diferenças. Afinal, são as próprias conexões apriorísticas que possibilitam a eficácia das determinações que lhes são contrárias.

As determinações jurídicas põem seu conteúdo como "devendo-ser" Não são afirmações do ser assim, ${ }^{37}$ ou ordens de conduta - o Direito Positivo não é ordem coativa.

As objeções levantadas contra o Direito apriorístico têm dois pontos de partida: a proposição de determinação ou o efeito da determinação.

A suposta contradição entre leis de essência e proposição de determinação não existe. Com efeito, só existe contradição entre conceitos da mesma espécie ou gênero - e que deveriam ter as mesmas características. Uma determinação, qualquer que seja seu conteúdo, não é capaz de contradizer uma situação essencialmente existente, podendo simplesmente ser diferente de uma situação existente por essência. A diferença eventualmente existente entre o que é e o que deve ser pode até ser fonte da determinação, agindo esta para retirar a força da lei a priori. Portanto, é efeito deste ato o fato de que a conexão a priori - de que toda promessa seja fonte de pretensões e obrigações, por exemplo - seja válida sem exceção, exceto quando disposto de outro modo em determinação efícaz.

As determinações do direito positivo põem a situação de dever-ser, transformando-a em ser. ${ }^{38}$ Mas esta transformação não é a única função do Direito. Além de criar direitos e obrigações, cuida o Direito em garantir sua realização. "El derecho positivo tiene la misión de cuidar de la existencia de lo de tal manera ordenado, $o$ de la posibilidad de existencia de lo permitido" " ${ }^{39}$ Este é papel assumido pela tutela juridica, através de ações (judiciais) que visam obter a conduta pretendida através da coação.

O Direito Positivo, ao contrário das leis de essência, eternas e imutáveis, pode vincular suas determinações à Justiça ou a necessidades da sociedade, mas, também, pode interpretar certos atos indeterminados como atos sociais determinados - por exemplo, ao equiparar a compra e venda de um imóvel a uma promessa com pagamento futuro (o que não é possivel segundo as leis apriorísticas).

$O$ verdadeiro conflito entre leis não é aquele tradicionalmente concebido pela Filosofia do Direito, mas sim, dentro da doutrina apriorística do Direito, aquele conflito entre uma lei de essência (lei do ser, algo que simplesmente é de tal forma) e uma lei do Direito Positivo, que não passa de uma determinação, sendo que a lei existe

37. Esta $\mathfrak{c}$ uma diferença entre as determinações $\mathrm{c}$ as leis essenciais do Dircito aprioristico.

38. V. colocação de K. Larenz sobrc o positivismo no itcm 6.

39. REINACH, Adolph, Los fiundamentos aprioristicos del derecho civil, Barcelona, Bosch, 1934, p. 190. 
apenas em relação àquela determinação. O conflito existiria, portanto, entre o ser e 1 dever-ser. Importante ressaltar que, por sua própria natureza, as leis a priori possuen prioridade lógica em relação às determinações do Direito Positivo. Como pode o qu existe no mundo ser diferente do ser, apesar desta prioridade lógica? O que existe $\mathrm{n}$ mundo é o que é conhecido, e depende do desenvolvimento da própria ciência que ، conhece. É este o problema do conhecimento - tal como apresentado por E. Husser] como alcançar a essência do ser.

Não é contraditório o conflito entre uma lei do Direito Positivo e uma le apriorística. O que ocorre é a modificação desta lei apriorística por uma determinaçã eficaz que produz uma lei, que existe, no entanto, somente em decorrência dest: determinação, e numa relação de dependência com esta. Haverá correspondência entrı lei apriorística e lei positiva, quando o ser for também o dever-ser. Somente existı diferença entre ambas, quando tal situação for desejável em consideração à totalidadı das relações sociais, econômicas, políticas e morais. Persiste, porém, a prioridade lógic: do Direito apriorístico, da mesma forma como existe prioridade lógica, segundo $\mathrm{E}$ Husserl, entre as ciências de essências e as ciências de fatos.

A esta prioridade lógica soma-se uma certa prioridade psicológica. $\mathrm{O}$ sujeitos determinantes - os legisladores - são freqüentemente condicionados pelo qu “é", recusando-se muitas vezes a determinar que o que deve ser seja em lugar do que । em si e para si. Ainda, os sujeitos agem freqüentemente segundo o que é, embora o se não corresponda, segundo o Direito Positivo, ao que deve ser. Este fenômeno é chamadı por A. Reinach de ontologismo. ${ }^{40}$

No desenvolvimento do Direito Positivo ocorre uma "emancipaçã interna" das leis apriorísticas do ser ao serem incorporadas ao Direito Positivı determinações que, embora não correspondam ao ser, são desejadas pelo tráfico social Tampouco é necessário o reconhecimento da existência das leis apriorísticas pelo homens para que estas efetivamente existam e sejam válidas.

Ao lado das determinações válidas e eficazes enquanto forças criadora de existência, existe a natureza e também os fatos nela existentes. Em relação a este fatos, demonstráveis empiricamente, podem agir considerações de valor, através d determinações, que os desejem como não-existentes. Neste caso, não atua a forç: criadora e soberana da determinação, mas, sim, atua a ficção. Se um fato da naturez: produz determinado efeito jurídico considerado indesejado, pode-se, através de um: determinação, extinguir seu efeito, ou, através de uma ficção jurídica, considerar । fato como não-existente. Isto ocorre por não ser a determinação capaz sempre de altera a realidade, a natureza das coisas.

Para obter tal resultado, utiliza-se o direito da ficção, como que ignorandı o mundo real. Um exemplo é o problema da pessoa jurídica. ${ }^{41}$ É lei de essência, comı

40. REINACH, Adolph, Los fundamentos aprioristicos del derecho civil, Barcelona, Bosch, 1934, p. 20.

41. H. Kelsen aponta a tentativa da doutrina de demonstrar que as pessoas juridicas, ao lado da pessoas naturais, são pessoas reais. "Mas estas tentativas são tanto mais baldadas quanto é certo que 
vimos, que somente pessoas possam ser titulares de direitos e obrigações pela natureza dos atos sociais envolvidos. Uma determinação, ainda que plenamente válida e eficaz, não pode alterar esta legalidade essencial de forma a transformar algo em pessoa. Quando o Direito Positivo atribui direitos da personalidade à pessoa juridica ${ }^{42}$ não lhe é capaz de atribuir personalidade, mas sim a trata como se personalidade tivesse. ${ }^{43} \mathrm{~A}$ personalidade atribuída à pessoa jurídica não deve ser confundida com a personalidade de seus membros - embora pela ordem juridica positiva seja possível a desconsideração da personalidade jurídica. De acordo com o Direito Positivo, pessoa jurídica e pessoas fisicas são pessoas diferentes, embora essencialmente a existência de pessoas jurídicas seja impossivel.

A. Reinach afirma, ainda, que o problema da pessoa juridica, ou seja, se é ou-não efetivamente pessoa, com personalidade diversa da de seus membros, só pode ser tido como problema se pressuposta a existência de conexões juridicas apriorísticas. Tal problema não tem sentido para aqueles que não consideram nada existente além do Direito Positivo.

Podemos concluir que o Direito Positivo tende a utilizar-se cada vez mais das formações jurídicas puras, ainda que sejam estas independentes de todo direito vigente e (moralmente) válido, pela simples razão que não há como ser de outra forma: é dado evidente da consciência. O Direito puro é superior ao positivo, mas não por razões jurídicas ou morais, mas por razões filosóficas. As proposições de Direito apriorístico devem ser tidas como juízos sintéticos a priori de I. Kant, como os conceitos de matemática pura. No entanto, não se desenvolvem necessariamente na natureza através da experiência. São, portanto, totalmente independentes e indiferentes ao Direito Positivo e à sua própria verificação, nem podem ser deduzidas do Direito Positivo. Não se trata, também, de acreditar na existência do Direito puro. É preciso investigar fenomenologicamente até se atingir a evidência intelectual necessária.

uma análise mais profunda revela que também a chamada pessoa fisica é uma construção artificial da
ciência juridica, que também ela é apenas uma pessoa juriclica'" (KELSEN, Hans, Teoria Pura do
Direito, Martins Fontes, Sào Paulo, 1998, p. 192). O conceito de pessoa, para H. Kclscn, tcm como
função atribuir a qualidade de portador de dircitos c obrigações a um ser humano ou cntc. Na verdade, a
personalidade ć csta concentração de normas juridicas, atribuindo dircitos ou obrigações, num mesmo
sujcito. Por csta razão, ambos os conccitos - pessoas fisicas c juridicas - são construções artificiais do
Dircito Positivo.

42. “... Direitos da Personalidade dizem-se as faculdades juridicas cujo objeto são os diversos aspectos" da própria pessoa do sujeito, bem assim seus prolongamentos e projeçöes" (FRANÇA, Rubens Limongi, Direitos da personalidade-Coordenadas fundamentais, RT 667/9). Sobre o alcance das pessoas juridicas pelos dircitos da personalidade, afirma C. A. Bittar que, uma vez sendo as pessoas juridicas cntes dotados de personalidade segundo o Código Civil, "fazem jus ao reconhecimento de alribulos intrinsecos à sua essencialidade, como, por exemplo, os direitos ao nome, à maica, a simbolos e à homra" (BITTAR, Carlos Alberto, Os direitos da personalidade, $5^{\text {म }} \mathrm{cd}$., Rio de Janciro, Forcnsc Universitária, 200I, p. I3).

43. Art. 52 do novo Código Civil (Lei 10.406/02): "Aplica-se às pessoas juridicas, no que couber; a proteção dos direitos da personalidade". 
5. Relação entre Direito e Estado: Direito apriorístico e Justiça.

Tendo-se em consideração as diferenças essenciais existentes entre Direito Positivo e Direito apriorístico, bem como entre Direito Natural e Direito apriorístico, cabe-nos agora refletir sobre a relação existente entre Direito apriorístico e Justiça.

A. Reinach afirma apenas, brevemente, não ser possível estabelecer qualquer relação entre Direito apriorístico e Justiça, uma vez sendo esta última um valor moral. ${ }^{44}$

No entanto, o mesmo tema encontramos na obra de E. Stein, Eine Untersuchung über den Staat. ${ }^{45}$ Cumpre salientar que E. Stein ${ }^{46}$ jovem intelectual judia, foi aluna de E. Husserl e de A. Reinach. Enviada por E. Husserl ao funeral de A. Reinach, E. Stein foi incumbida pela viúva de organizar seus últimos escritos, tendo assim estudado profundamente a obra de A. Reinach. E. Stein foi morta em 7 de agosto de 1942, no campo de concentração de Auschwitz, Polônia, tendo sido canonizada, em 11 de outubro de 1998, pelo papa João Paulo II como Santa Teresa Benedita da Cruz.

E. Stein afirma, primeiramente, que a expressão "direito" pode ser utilizada de duas formas. A primeira, indicando um "estado de direito" (Rechtsverhalte) que existe independentemente de qualquer ato de arbítrio, e independente também de ser reconhecido por alguém como direito vigente - este é o Direito puro. "A côté de ce droit il y a le droit en vigueur, le droit dit positif. Le droit pur est le même en tous temps et dans toutes les cultures; pérenne, il n'est pas proclamé à un moment donné. En revanche, le droit positif est une creation ou une application arbitraire, ce qui lui vaut d'être largement diversifié" 47

Tanto o Direito puro quanto o Direito Positivo têm o mesmo objetivo: regular a conduta humana. O Direito Positivo é válido quando este objetivo, com realidade temporária, é reconhecido. No entanto, a existência mesma do Direito puro não se confunde com a validade do Direito Positivo. Esta tem começo e fim, o que não se aplica ao Direito puro, que é atemporal. A relação existente entre Direito puro e Direito Positivo é, portanto, a relação existente entre essência e fato.

O Direito puro, ainda, pode "se realizar" ou seja, tornar-se positivo. O legislador, reconhecendo um valor em determinada situação pode tornar positivo o 224.

44. REINACH, Adolph, Los findamentos aprioristicos del derecho civil, Barcelona, Bosch, 1934, p.

45. Foram utilizadas edição $\mathrm{cm}$ alemào (STEIN, Edith, Eine Untersuchung über den Staat, Tübingen, Max Niemcyer, 1970), como complementação, c principalmente a cdição en francês (STEIN, Edith, $D e$ l'Etat, Fribourg, Les Éditions Universitaircs, 1989).

46. As informaçõcs biográficas sobrc E. STEIN foram obtidas no site da lnternet www. carmelnct.org/ sword/v58/08.htm.

47. STEIN, Edith, De l'Etat, Fribourg, Les Éditions Universitaircs, 1989, p. 64. 
Direito puro. O primeiro direito puro posto em vigor é, portanto, o direito de legislar, pois a partir do direito de legislar é que podem os demais direitos puros ser positivados.

Os atos legislativos (leis) impõem ou indicam certa conduta a um sujeito, sendo formulados, no entanto, como ordens, e sim como proposições teóricas e que "indique une norme d'action imposée aux individus relevant du domaine d'autorité où elle est em vigueur, et plus particulièrement à ceux qui sont chargés de faire especter le droit". ${ }^{48}$ Quando se reconhece o quanto estabelecido por tal proposição teórica, o Direito é efetivamente executado - este é o domínio de validade da legislação. No entanto, difere de algo prescrito com necessidade, que é o caso da formação jurídica pura. Neste último caso, o caráter de necessidade é inerente à coisa, e em relação ao Direito puro a disposição normativa e a execução do prescrito é que lhe são conforme. Geralmente, não é o Direito Positivo derivado do Direito puro, mas sim decorrente da arbitrariedade do legislador. A obediência ao Direito Positivo, por outro lado, não significa desobediência ao evidente, mas sim submissão à vontade do legislador.

$\mathrm{O}$ "eu" é centro de acontecimentos psicológicos, nascidos necessariamente de certos contatos com o mundo exterior, contra o qual existe um movimento contrário interior. Pode ocorrer que a espontaneidade não participe, o que, porém, não é sempre possível. Não existe, por exemplo, uma resolução arbitrária mas podem existir diferentes razões para tal resolução. É possível, por exemplo, que o sujeito atuante - no caso o legislador - tenha uma percepção clara, no sentido de intuição pura, que sirva de fundamento a um estado-de-valor reclamado e a ser realizado através de sua transformação em Direito Positivo. Opera, assim, o sujeito como executor de normas absolutas: é o que ocorre ao legislador, quando proclama uma lei que também é formação de Direito puro. Seu efeito tem alcance social, sem, no entanto, ter como objeto direto o comportamento de pessoas.

Ao lado desta possibilidade, pode também ocorrer que seja o Direito Positivo completamente indiferente ao Direito puro, transformando em Direito apenas o que é desejado por alguns indivíduos.

Necessário verificar agora quem é o sujeito capaz de realizar tais atos espontâneos - atos legislativos. "Un acte spontané est um libre agir spirituel, et nous appelons "personne" le sujet d'um tel agir.. Nous avons dit de l'État que'il est souverain, ce qui signifie que 'il lui-même l'acteur de son droit" 49 Para que isto seja possível é necessário que o Estado, enquanto comunidade, ao mesmo tempo, seja sujeito e objeto do direito em vigor. Somente um grupo de indivíduos livres pode declarar sua soberania e seu domínio de autoridade, formando o Estado. Porém, o Estado não se restringe à comunidade anteriormente estabelecida.

A atividade do Estado não se esgota no ato de legislar, utilizado pela autora apenas para iluminar a relação entre Direito e Estado. Para tanto, utiliza E. Stein a diferença entre determinação e comandos ou ordens - a mesma de A. Reinach. As

48. STEIN, Edith, De l'Etal, Fribourg, Les Éditions Universitaircs, 1989, p. 64.

49. STEIN, Edith, De l'Etal, Fribourg, Les Éditions Universitaires, 1989, p. 67/68. 
determinações são dirigidas a todos os membros submetidos à esfera de domínio estata buscando em relação à uma certa pessoa tal conduta. Entre a determinação e comportamento da pessoa que a reconhece e cumpre está o Direito Positivo.

Para o Estado, porém, os atos sociais apresentados como ordens sã importantes, mas exigem complementação de outros tipos de atos - as determinações No entanto, a determinação deve servir de guia dos comportamentos possíveis, ser visar efetivamente à específica conduta humana. Por esta razão, não é o direit obrigatório. No entanto, sendo a ordem ato alheio-pessoal, deve o cidadão a quem s dirige entender, compreender e realizar o ordenado. Devem tais atos possuir, portantc publicidade. A ordem, por sua vez, de tornar tais atos públicos é dirigida não a todos mas àqueles incumbidos de tal tarefa pelo Estado.

A interpretação do conteúdo das determinações deve ficas obrigatoriamente, a cargo do Estado, ou de quem este determine, sob pena de estar soberania estatal (pela interferência legiferante de pessoa estranha ao Estado) maculada A interpretação dada pelo Estado é conteúdo de determinação posterior à determinaçãı interpretada. Não pode o Estado,'portanto, desincumbir-se de tal tarefa. "L'interpretatio des dispositions et les décisions théoriques concernant les différents cas qui tomben dan son domaine d'application pourraient se résumer sous le titre de « jurisdiction . (Rechtsprechunf), opposable à la législation (Rechtssetzung) - à la promulgatio originaire de dispositions" 50

Os atos teóricos envolvidos na interpretação de uma determinação nãı são espontâneos no mesmo sentido dos atos legislativos. A lei que se impõe por atı isolado do legislador não é equivalente ao nosso arbítrio. É certo que o intérprete utilizar: sua espontaneidade ao interpretar e analisar o caso concreto e as determinações en jogo. O trabalho teórico envolvido na interpretação das determinações não significa para a jurisdição estatal, um fim em si mesmo, mas sim tendo como função torna possível a aplicação do direito vigente - produção de norma jurídica individual. " $L$ jurisdiction ne fait pas que décider, elle declare. Ainsi elle s'addresse directement au. individusconcernés et etáblit le contact, ce qui manque aux dispositions en tant qu. telles" ${ }^{53}$

A jurisdição, enquanto execução das determinações, pode ainda se completada por atos que, embora não lhe digam respeito, possibilitam o cumpriment de suas decisões: "appels, avertissement, ordres adressés nominalement, menaces sanctions, punition" 52 Tais atos, juntamente com os atos legislativos e a jurisdição são englobados pela Jurisprudência (Rechtspflege).

Ao lado de seu poder legislativo, atua também o Estado comı empreendedor, declarando guerra, colonizando outros países, desenvolvendo política econômicas, criando escolas ou instituições sociais etc. Nestes casos, age o Estadı

50. STEIN, Edith, De l'Etat, Fribourg, Les Éditions Universitaircs, 1989, p. 75.

51. STEIN, Edith, De l'Etat, Fribourg, Les Éditions Universitaires, 1989, p. 76.

52. STEIN, Edith, De l'Etal, Fribourg, Les Éditions Universitaircs, 1989, p. 76. 
livremente, sem necessitar de atos legislativos para tanto, através de comandos chamados de atos de governo. Tais atos são espontâneos e requerem o consentimento do comandado, razão pela qual, por dever ser o comandado livre para consentir, não pode o Estado eliminar a liberdade de alguém. Os atos de governo são, assim como os atos legislativos, objetos essenciais, e uma espécie de ato complementa o outro, enquanto instrumentos de execução.

Pode-se dizer que possui o Estado o direito de elaborar ordens. O primeiro direito, como afirmado acima, é o direito de legislar. A este direito podemos somar o direito a governar. Porém, uma vez que o próprio Estado possui tais direitos, seu ato de constituição precederia a existência do Direito, de modo que não seria o Estado legalmente constituído. No entanto, ao colocar um ato, o Estado o reivindica como seu direito: "l'État et le droit naissent simultanemént. Cela signifie: là où il y a um État, il y a aussi, selon l'idée, um droit positif, même si aucune disposition légale n'a encore èté énoncée". 53

Por tudo quanto exposto acima, E. Stein conclui que é a soberania a essência do Estado. Tal soberania advém da própria liberdade dos indivíduos que o constituem. Esta liberdade, para que o Estado exista, não deve ser atingida, e deve a soberania estatal ser reconhecida por todos. A existência do Estado é, portanto, bastante frágil, por ser mesmo fundamentada por este reconhecimento. A garantia mais forte da "sobrevivência" estatal é a comunidade existente anteriormente ao Estado e ao Direito, regulando suas relações.

Uma vez estabelecida a estrutura particular do Estado, pode-se perguntar se está ou-não o Estado destinado à realização de certos valores. Como vimos, a missão própria do Estado é a realização do Direito puro, e não simplesmente da forma do Direito, que é o Direito Positivo. O Direito puro necessita, enquanto direito justo em si mesmo, do Estado para ser reconhecido, em sua esfera de dominação, como Direito em vigor. Portanto, a idéia de Justiça guarda relação intrínseca com o Direito puro. "Lá où le droit pur s'exerce, lá règne la justice" $\$ 4$

A Justiça é, portanto, um predicado de valor que se pode atribuir à uma ordem jurídica em vigor e que exprime a conformidade desta ao Direito puro. Porém, não é condição sine qua non do Estado a realização da Justiça. Por esta razão nem sempre coincide Direito puro e Direito Positivo, podendo o Direito em vigor ser tido como injusto.

6. Conclusão.

Tivemos um longo percurso percorrido até aqui. Toda a complexidade desta estrutura ôntica jurídica proposta por A. Reinach foi-nos apresentada, sem antes deixar de causar certa surpresa, surpresa esta própria do momento no qual algo evidente, até então ignorado, se nos apresenta.

53. STEIN, Edith, De l'Etat, Fribourg, Les Éditions Universitaircs, 1989, p. 79.

54. STEIN, Edith, De l'Etat, Fribourg, Les Éditions Universitaires, 1989, p. 145. 
A fenomenologia do Direito de A. Reinach, refletida em sua doutrin aprioristica, é uma nova proposta a problemas que já foram, de algum modo, consagrado pelo tempo, e também pelo fato de não lhes terem sido apresentadas respostas definitiva: A doutrina apriorística do Direito é, ainda, manifesto contra a idéia de um Direit Natural - e sua confusão com este - bem como, e especialmente, demonstração de su total independência em relação ao Direito Positivo.

À época de A. Reinach, o positivismo reinava absoluto em face de toda as demais teorias acerca da natureza do Direito. O pensamento neokantista, com tod sua gama de seguidores no final do século XIX e início do século XX, propunh considerar a realidade como um processo de transformação realizado pelo pensamentc que ora lhe atribuía o status de fato, ora lhe atribuía o status de valor. ${ }^{55}$ Assir apresentava-se a norma jurídica como um esquema de interpretação da realidade. "( que transforma este fato num ato juridico (licito ou ilicito) não é sua facticidade, na é o seu ser natural, isto é, o seu ser tal como determinado pela lei da causalidade encerrado no sistema da natureza, mas o sentido objetivo que está ligado a esse ato, , significação que ele possui... o juizo em que se enuncia que um ato de conduta human. constitui um ato jurídico (ou antijurídico) é o resultado de uma interpretação especifica a saber, de uma interpretação normativa" " 56 Para $\mathrm{H}$. Kelsen, esta significação jurídica emprestada a um fato por uma norma jurídica, por sua vez, é fundamentada em um outra norma, e assim por diante, até se alcançar a norma fundamental, que concentr toda a validade da ordem jurídica.

No entanto, o pensamento positivista guiado por esta visão neokantian do direito não responde a muitas das questões concernentes à ciência jurídica especialmente no que toca à existência de objetos que trazem em sua própria essênci algo que nos permita a priori classificá-los como jurídicos. "Mas será verdade que o diversos modos em que se nos apresentam as coisas da natureza inanimada, a vid. orgânica, as sensações e vivências animicas, as obras do espirito ou o comportament. significativo de uma pessoa, assentam apenas numa diferente maneira de conceber $d_{1}$ observador? Não se fundamentarão já, pelo contrário, ou não estarão já pré conformados, no próprio modo de ser, na própria estrutura "objectiva" desses dados?"

É neste cenário filosófico que surge a Escola Fenomenológica de $\mathrm{E}$ Husserl e sua busca pela essência das coisas, do ser enquanto o que ele é. Através d intuição - que é a ferramenta própria do pensamento filosófico - pode-se alcançar . que a simples percepção não alcança. Assim, o conhecimento supera os limites d. mundo natural, alcançando o que existe essencialmente. Estas essências são objetos . priori, munidos do caráter de necessidade e universalidade.

55. LARENZ, Karl, Metodologia da ciência do direito, Lisboa, Fundação Caloustc Gulbcnkiaı 1974, p.138/139.

56. KELSEN, Hans, Teoria Pura do Direito, São Paulo, Martins Fontes, 1996, pp. 4/5.

57. LARENZ, Karl, Metodologia da ciência do direito, Lisboa, Fundação Calouste Gulbenkial 1974, p. 138. 
A despeito de apenas E. Husserl ter sido capaz de desenvolver plenamente o método fenomenológico, muitos de seus discipulos aplicaram-no nos mais diversos campos do conhecimento. Assim, A. Reinach foi o único autor a, satisfatoriamente, se utilizar da fenomenologia para um estudo da ciência jurídica e seus objetos.

O Direito, para A. Reinach, não se restringe aos diversos ordenamentos jurídico-positivos em vigor. Na verdade, o Direito, assim como a matemática e a geometria, ultrapassa essa realidade fática limitada pelo Direito Positivo, visto que existem objetos jurídicos independentes de todo e qualquer Direito Positivo, melhor, de todo e qualquer mundo natural. Tais objetos jurídicos existem ainda que nada mais existisse, e são válidos para todo mundo pensável. Isto se dá pois são estes objetos jurídicos - e suas conexões e legalidades - essências, assim como o são os números para a ciência matemática.

A maior parte das ordens jurídicas reconhece que a promessa é fonte de pretensões e obrigações. Qual a razão de tal fenômeno? Além do mundo real, tal fenômeno jurídico se dá pois essencialmente a promessa é fonte de direitos e obrigações - ainda que o Direito Positivo assim não determinasse. Por outro lado, pela própria essência dos atos sociais envolvidos, não é possível que haja a cessão de pretensões (direitos relativos), dado sua natureza estritamente pessoal, embora o Direito Positivo assim admita.

Esta independência de todo e qualquer Direito Positivo não encerra a validade do Direito apriorístico. Com efeito, o Direito Positivo apenas "forja" certas realidades através de determinações. Estas realidades criadas pelo Direito Positivo existem apenas enquanto perdurar sua determinação/norma jurídica criadora. O mesmo não ocorre com o Direito apriorístico: este é marcado pela intemporalidade, pelo seu caráter de proposição universalmente válida e necessariamente verificável. "As figuras juridicas que Reinach tem em mente existem numa relação com determinadas pessoas, e numa determinada época. As suas formas estruturais, porém, têm um ser extratemporal e são portanto necessariamente anteriores ao Direito positivo enquanto tal" 58

Tais objetos jurídicos apriorísticos devem ser apreendidos pelo legislador através da intuição e transformados em Direito Positivo, aproximando, assim, o Direito Positivo (ciência de fatos) do Direito apriorístico (ciência de essências). Não deve, no entanto, servir-se o juiz do Direito apriorístico, visto ser o Direito Positivo, no limite estabelecido por sua vigência, soberano.

O Direito apriorístico, embora eterno e imutável, não deve ser confundido com o Direito Natural, em qualquer de suas correntes. O Direito apriorístico têm caráter lógico, como a matemática e a geometria - e outras ciências puras, não tendo qualquer relação com a moral. Seus conceitos não têm significação moral; pelo contrário, sua superioridade em relação ao Direito Positivo é filosófica, assim como são as ciências

58. LARENZ, Kaґl, Metodologia da ciência do direito, Lisboa, Fundação Calouste Gulbenkian, 1974, p. 140 
de essência superiores - embora independentes - em relação às ciências de fatos, uma vez existirem essências independentemente da realidade fática.

Pelo contrário, o Direito apriorístico existiria ainda que contra toda a moral existente. Não é a moral que possibilita sua existência, mas sim sua essência, que não permite que sejam as coisas de outro modo.

Por esta razão, não estabelece $A$. Reinach qualquer relação entre Direito apriorístico e Justiça. Mais uma vez, uma sutil diferença separa o Direito aprioristico das teorias jusnaturalistas: encontra o primeiro sua força na própria filosofia, em sua essência, no fato de não poder ser de outra forma. A Justiça, porém, encontra-se sempre ligada à moral, que não intemporal. No entanto, em E. Stein - e seu pensamento fortemente influenciado por sua conviç̧ão religiosa - encontramos o Direito puro como cerne da Justiça realizada em um Estado. Ainda assim, não adquire o conceito de Justiça contornos morais, significando apenas certo valor atribuído ao Estado - como Estado justo - que reconhece como Direito Positivo o Direito puro.

Não podemos nos esquivar ao enfoque totalmente revolucionário dado ao Direito por A. Reinach. Embora não tenha esclarecido totalmente a relação entre Direito apriorístico e Direito Positivo, a proposta de A. Reinach vai totalmente contra o confortável pensamento positivista. Confortável enquanto conivente de certa forma com ordens jurídicas, cuja validade repousa sobre a força, e não sobre a legitimidade própria do Direito. "Mas essa é a vantagem dos tiranos - impor pelo medo tudo o que dizem e fazem" 59

Enquanto ciência dotada de conceitos jurídicos puros, o Direito encontraria, enfim, sua própria natureza e fundamento. Estaria o Direito repousado na filosofia que misteriosamente permite o acesso de seres limitados ao infinito, através do conhecimento, e teria como função primordial regular relações humanas de acordo com a própria natureza dos atos praticados - nem mais, nem menos.

Podemos afirmar que somente através da fenomenologia pode-se admitir a existência da filosofia, sem restringi-la a recapitulações de momentos historicamente relevantes para o pensamento humano. E, admitindo a existência da filosofia, nos moldes do pensado por A. Reinach, tem-se o Direito apriorístico, superior e indiferente às necessidades humanas, válido para todos e para ninguém.

São Paulo, agosto de 2002.

Bibliografia.

BITTAR, Carlos Alberto, Os direitos da personalidade, $5^{\mathrm{a}}$ ed., Rio de Janeiro, Forense Universitária, 2001.

FLUSSER, Villem, Lingua e realidade, São Paulo, Herder, 1963.

FRANÇA, Rubens Limongi, Direitos privados da personalidade, RT 567. 
HUSSERL, Edmund, A ideia da fenomenologia, Lisboa, 70, 2000. , Doutrina do Direito, São Paulo, Cone, 1993.

, Edmund, Pure phenomenology, its method and its fields of investigation, Notre Dame, University of Notre Dame, 1981. , Ideas relativas a una fenomenologia pura y una filosofía fenomenologica, Cidade do México, Fondo de Cultura Económiza, 1997.

KANT, Immanuel, Crítica da razão pura, Rio de Janeiro, Ediouro.

KELSEN, Hans, Teoria Pura do Direito, São Paulo, Martins Fontes, 1996.

LARENZ, Karl, Metodologia da ciência do direito, Lisboa, Fundação Calouste Gulbenkian0, 1974.

REINACH, Adolph, Fundamentos aprioristicos del derecho civil, Barcelona, Bosch, 1934.

SÓFOCLES, Antigona, São Paulo, Paz e Terra, 1999.

STEIN, Edith, De l'Etat, Fribourg, Les Éditions Universitaires, 1989. 1970. , Eine Untersuchung über den Staat, Tübingen, Max Niemeyer, 